\title{
Innovation and Cost Efficiency in the Banking Industry: the Role of Electronic Payments ${ }^{1}$
}

\author{
Guerino Ardizzi ${ }^{\dagger}$, Federico Crudu $^{\ddagger}$ And CARMelo Petraglia ${ }^{\S}$ \\ ${ }^{\dagger}$ Market and Payment System Oversight Department, Bank of Italy. Via Milano, 60/G Rome, 00183 Italy \\ (e-mail: guerino.ardizzi@bancaditalia.it) \\ * Department of Economics and Statistics, University of Siena, Instituto de Estadística, Pontificia \\ Universidad Católica de Valparaíso and CRENoS. Piazza San Francesco 7-8, Siena, Italy (e-mail: \\ federico.crudu@unisi.it) \\ ${ }^{\S}$ Department of Mathematics, Computer Science and Economics (DiMIE), University of Basilicata, \\ Viale dell'Ateneo Lucano 10, 85100, Potenza, Italy (e-mail: carmelo.petraglia@unibas.it)
}

\begin{abstract}
This paper presents new evidence on the assessment of banks' cost efficiency gains stemming from ICT adoption. With respect to the existing literature we introduce two novelties. First, banking operating costs are explained in terms of a commonly used measure of IT innovation (the relative diffusion of ATMs) and a new variable defined as automated payment transactions. Second, the results obtained via standard parametric estimation methods are compared with those obtained via nonparametric estimation techniques. Using an original dataset of Italian banks observed in the period 2006-2010, we do not find clear cost efficiency enhancing effects due to ATMs diffusion. On the other hand, the diffusion of electronic payments shows a significant effect in terms of cost inefficiency reduction.
\end{abstract}

Keywords: electronic payments, ATM, bank cost efficiency, nonparametric regression, ICT adoption.

JEL classification numbers: C14, C33, G2, L8, L11.

\footnotetext{
${ }^{1}$ We wish to thank David Humphrey, Ettore Panetti and Giuseppe Lubrano for their helpful comments. Federico Crudu's research is funded by CONICYT - Proyecto FONDECYT Iniciación en Investigación N. 11140433 .
} 


\section{Introduction}

The role of ICT adoption and technological change in banking activity has received remarkable attention in the literature (see, for instance, Berger 2003; Humphrey et al. 2006; Casolaro \& Gobbi 2004; Frame \& White 2012 for a survey). In this context, the utilization of ICT for retail payment services is an excellent angle from which to assess the spread of new technologies among economic agents (Hasan et al.2012). Indeed, innovations in retail payments imply the automation of both the inter-bank procedures and the internal banking processes and products, with positive spillovers for bank efficiency and customers' safety (e.g. Fung et al. 2014). Moreover, in the European context, the bank provision of electronic payments in substitution of cash and other paper based procedures - which has been reinforced by the project of a Single European Payment Area (SEPA) - is considered both as an opportunity to reinforce the retail banking activities, and as an important driver for cross selling strategies with loans and deposits ${ }^{2}$ Despite the relative importance and technological innovation in the field of payment markets, the empirical literature on retail payments and banking efficiency is rather scant (Humphrey et al.2006). The issue is becoming more and more relevant after the last financial crisis, the fall in the net interest income, the new competition challenges worldwide and the more stringent prudential supervision requirements (the so called "Basel III" requirements) which may further reduce degrees of freedom in searching profits.

The aim of this paper is to provide new evidence on the positive link between fully automated payment processing procedures and overall operating costs at the bank level. To the best of our knowledge, this is the first study using observed data on electronic

\footnotetext{
${ }^{2}$ Regarding the screening of European banks, Ayadi et al. (2012) find that "diversified retail" banks (using diversified sources of funding and providing predominantly customer loans) are safer than others allowing for lower default probability and long-term liquidity risks.
} 
payments, where the available evidence relies on automated teller machines (ATMs) data. We find evidence of banks' cost efficiency gains stemming from the use of IT payment channels applying nonparametric estimation techniques to an original dataset of 2708 observations on Italian banks or banks operating in Italy observed over the period 2006-2010.

Three previous studies are most related to ours. We depart from each of them in different aspects. Haynes \& Thompson (2000) find a positive productivity effect of the adoption of ATMs in a panel of 93 UK building societies observed over the period 19811993. They estimate an augmented Cobb-Douglas production function where a dummy variable accounts for the adoption of ATMs in a given year. Ou et al. (2005) and $\mathrm{Ou}$ et al. (2009) focus on ATMs intensity rather than ATMs adoption by using a quantitative measure of ATMs diffusion (ATMs per employee) in a cross section of 264 banks in Taiwan. OLS estimates show that higher diffusion on ATMs is associated with lower cost inefficiency. Departing from the above mentioned studies we use two quantitative measures of the degree of IT innovation at the bank level. The first measure is given by the relative incidence of the number of ATMs owned by the bank to the number of its ATMs and physical branches over the counter (OTC). The second measure is the share of electronic transactions to the total of payment operations managed by the bank. We believe that the combined use of these two variables provides a more appropriate way to measure the 'actual' degree of IT innovation at the bank level, while the relative endowment of ATMs alone can be regarded only as its 'potential' counterpart. The beneficial effect of a larger expansion of ATMs relative to branch offices combined with the shift to electronic payments has been found by Carbó-Valverde et al. (2006) for a sample of 93 commercial and savings Spanish banks over the 1992-2000 period. These authors use bank-specific information on operating cost, number of ATMs, branch 
offices, and labour and capital input prices. On the other hand, information on the means of payment (the number of check, giro, and card payments) is available only at the aggregate (national) level. All the aforementioned papers share the common feature of using parametric estimation methods. They need to impose a functional form to the production (cost) function augmented in order to accommodate for the presence of the IT input. We do not need to do so as our estimates are nonparametric. It is worth noticing that the use of nonparametric estimation techniques is a relevant novelty in this field.

The remainder of the paper unfolds as follows. In Section II. we present our model and formulate testable hypotheses for our two measures of IT innovation. Section III. presents our data, reporting the definitions and descriptive statistics for all relevant variables included in the estimated models. Estimates and results are presented and discussed in Section IV. Section V. concludes with a discussion of the policy implications of this study.

\section{Modelling the impact of innovation on bank cost ef- ficiency}

Studies on the impact of IT innovation on bank efficiency usually consider the diffusion of ATMs as a proxy of innovation (Haynes \& Thompson 2000; Ou et al. 2005; Ou et al. 2009). However, such an approach may lead to overestimating cost savings. Indeed, the availability of ATMs alone does not necessarily imply a lower usage of traditional means of payments which depends on the attitude of clients towards electronic payments.

In line with previous studies (see, for instance, Carbó-Valverde et al. 2006), our 
measure of cost inefficiency is:

$$
\text { costratio }=\frac{\mathrm{OC}}{\mathrm{TA}}
$$

where $\mathrm{OC}$ indicates operating costs, TA total assets, and a lower value of costratio corresponds to higher cost efficiency. Our aim is to assess the impact of the IT payment channel innovation on the bank efficiency overall. Accordingly, we define a single equation model where the logarithm of costratio (logcostratio) is the dependent variable to be linked to a set of explanatory variables. We assume that in order to assess the impact of IT innovation on cost efficiency one should consider the relative technological endowment of the bank as well as the actual usage of it. The first aspect is captured by the variable atmshare defined as the relative incidence of the number of ATMs owned by the bank to the number of its physical branches OTC and ATMs. This is our first indicator of payment channel innovation in bank services, reflecting the endowment of infrastructure available to the bank as a result of its past IT investment. A higher ratio means a greater ATM intensity and a higher probability to process electronic cash operations, which are more efficient than OTC ones (Bank of Italy 2012). This variable is expected to affect costratio negatively, according to the following hypothesis:

Hypothesis 1 The higher the diffusion of the ATM network, the lower costratio (the higher cost efficiency) due to less costly automated channel for the management and handling of banknotes, ceteris paribus.

Our second IT innovation explanatory variable is elettroratio, defined by the share of electronic transactions to the total of payment operations managed by the bank. The use of this variable, which represents a novelty with respect to previous studies, is ex- 
pected to improve on available evidence as it is more directly linked to the actual usage of electronic transaction technologies. Studies on banking efficiency usually consider the diffusion of ATMs as a proxy of innovation (Haynes \& Thompson 2000, Ou et al. 2005, Ou et al. 2009). However, cash and other paper based instruments emerge as the most costly instruments on the bank side (Bank of Italy 2012), above all owing to the hefty costs for the management and handling of the paper documents (deposit, transportation, reconciliation, etc.). A number of reasons motivate the inclusion of elettroratio in our model. For instance, Bank of Italy (2012) and Schmiedel et al. (2012) claim that indicators referring to the various channels of access to transactions highlight the possible efficiency gains of a shift to the electronic channel: the average unit cost of traditional payment instruments (i.e. paper based credit transfers, checks, collecting items) is almost three times that of straight-to-processing (STP) orders, due to administrative costs arising from the large number of manual operations involved in the payment process. Central bankers' speeches (see for instance Panetta 2013) underline that innovative payment channels can be used for the distribution of highly standardized, low-value-added transaction-based services, such as liquidity management and consumer finance products, especially to the more technologically or financially advanced customers, that can generate more value-added and reduce costs. Accordingly, elettroratio should be consistent with the following hypothesis:

Hypothesis 2 The higher the share of actual full automated payment transactions managed by the bank, the lower costratio and the higher cost efficiency due to less costly automated channel and positive spillover within the bank, ceteris paribus.

In Section IV. we will specify and estimate several models for a sample of Italian banks observed over the period 2006-2010 in order to test the above hypotheses. First of all, we 
will estimate the baseline model, including variables measuring the two IT determinants of cost efficiency described above. In line with previous empirical studies on this issue, we will also estimate an extended model, including other two additional covariates in order to control for bank size and labour cost.

Bank size will be proxied by total assets owned by the bank $]^{3}$ The empirical literature on the link between bank size and cost efficiency includes mixed results. One argument in favour of higher efficiency of larger banks is that with size scale economies also increase. On the other hand, smaller local banks usually operate in small and protected markets, benefiting from a more efficient selection of reliable customers and lower levels of competition. This is also consistent with the view that small banks (especially cooperative and local/rural banks) are less innovative in their business models and more affected by local market specificity (Kwan \& Eisenbeis 1996). Overall, especially in the Italian case, more than size alone, the ownership structure, the geographical location, the type of relationship with customers (relation- vs. transaction- models) matter. For instance, Giordano \& Lopes (2009) estimate cost and profit efficiency of Italian banks in 1993-2003 and find that small and medium-sized mutual banks located in the Centre and North of Italy show the best performance in costs and profitability, while large incorporated banks in the South perform worst. Given all the above considerations, in our model the effect exerted by bank size on cost efficiency is expected to be undetermined a priori:

Hypothesis 3 The higher the total assets owned by the bank, the higher/lower cost efficiency, ceteris paribus.

We finally maintain the assumption that most efficient banks are those making higher

\footnotetext{
${ }^{3}$ Total assets include cash balances, financial assets for trading, loans with banks and customers, financial investments, property, plant and equipment and intangible assets.
} 
efforts to control salary expenses, in line with the empirical evidence provided by several studies, e.g. Spong et al. (1995), Berger \& Humphrey (1997) and Bikker (2004). This also suits the Italian case as, according to the Bank of Italy (2014), the relative higher ratio of operating expenses to total assets of the Italian banking industry $(1.8 \%$ against $1.3 \%$ of the Euro area average) is largely due to greater relative importance of labour-intensive and branch-based retail business. Thus, we put forward our last testable hypothesis:

Hypothesis 4 The higher salary expenses of the bank, the higher costratio (the lower cost efficiency), ceteris paribus.

\section{Data}

Our analysis is conducted on a data set provided by the Bank of Italy. We consider an unbalanced panel of 2,708 observations in the period between 2006 and 2010, where we have information about 651 banks and other financial institutions operating in Italy. The considered time span allows to identify long-run cost differences among banks rather than short-run anomalies. Table 1 provides the definition of all variables included in estimated models.

Table 1 about here

Table 3 shows descriptive statistics for the sample as a whole. Table 4 and Table 5 report the same statistics disaggregated by year and bank size, respectively. Figure 1 depicts the time path of costratio controlling for bank size. These descriptive evidence help to highlight some relevant facts occurred over the considered period in the Italian banking system. From Table 4 we observe the sharp increase in salaries. Other 
things being equal, this effect would imply lower cost efficiency. On the other hand, our two measures of IT innovation show an increasing time trend, thus leading to expected cost efficiency gains. By looking at the relatively flat time trend of costratio, one should conclude that, in the full sample, cost savings associated with IT innovation have been offset by the increase in salaries. However, this descriptive evidence should carefully take into account differences across banks, most of them being proxied by TA. From Table 5 we observe that cost efficiency seems to increase with size: the mean of costratio decreases from 0.028 (minor banks) to 0.021 (major banks). Such a pattern seems to be driven by efficiency gains due to IT innovation that compensates for higher salary expenses. The red and black curves shown in Figure 1 1illustrate how costratio varies as a function of $\log$ TA in 2006 and 2010, respectively. The two curves are obtained by means of nonparametric local linear regression with cross-validated bandwidth. Only banks after a threshold value of logTA have experienced significant cost gains, while below that value we observe an efficiency loss. This descriptive evidence calls for controlling for bank size in our estimated model.

Table 2 about here

Table 3 about here

Table 4 about here

Table 5 about here

Figure 1 about here

Figure 2 about here 
It is finally worth noticing that our variables (with respect to size) show very skewed distributions and their density seems to be higher for minor banks (see Figure 2). The high density for minor and small banks is due to the high fragmentation of the Italian banking system which - despite mergers and acquisitions - is characterized by a large number of credit institutions and a large share of cooperative and local/rural banks (about 700).

\section{Estimation and results}

We concentrate our attention on the cost-efficiency indicator logcostratio against two technological variables, the first (elettroratio) takes into consideration the number of ATMs and the second (atmshare) takes into account the number of electronic payments. As argued in Section II., we expect these two variables to have a negative impact on inefficiency. On the other hand, we expect wages (logwage) to have a positive impact on the inefficiency variable..$^{4}$

\section{Parametric models}

Table 6about here

We consider the following model

$$
\begin{aligned}
\operatorname{logcostratio}_{i t} & =\beta_{0}+\beta_{1} \operatorname{logwage}_{i t}+\beta_{2} \text { elettroratio }_{i t} \\
& +\beta_{3} \text { atmshare }_{i t}+\beta_{3} \operatorname{logTA}_{i t}+\alpha_{i}+u_{i t}
\end{aligned}
$$

\footnotetext{
${ }^{4}$ The numerical results are obtained by means of the $\mathrm{R}$ packages plm and np. See Croissant \& Millo (2008) and Hayfield \& Racine (2008).
} 
where the index $i$ refers to banks and $t$ refers to time 5 The model is first estimated by pooled OLS. Then, in order to consider the panel features of the data we estimate the model both with a fixed effects (FE) estimator and a random effects (RE) estimator. It is possible that the marginal effects may not be linear and vary across the domain of the covariates. Therefore, we augment the model in equation (1) by including squares and cubes of the regressors and estimate the following model:

$$
\operatorname{logcostratio}_{i t}=\beta_{0}+\sum_{x \in A} \beta_{1}^{(x)} x_{i t}+\sum_{x \in A} \beta_{2}^{(x)} x_{i t}^{2}+\sum_{x \in A} \beta_{3}^{(x)} x_{i t}^{3}+\alpha_{i}+u_{i t}
$$

where $x \in A$ and $A=\{$ logwage, elettroratio, atmshare, logTA $\}$. In order to provide the reader with a better comparison among the various estimators we consider also the Arellano-Bond (AB) estimator (Arellano \& Bond 1991) .6 The AB estimator is a standard tool in applied econometrics and allows us to consistently estimate our parametric model in the presence of endogeneity.

From the parametric regressions reported in Table 6, the estimated (linear or first order) coefficients have the expected sign and are statistically significant at the $1 \%$ level suggesting the validity of our hypotheses in Section III. This is generally true both considering the static models (first column associated to each estimator in Table 6) and the dynamic model (second column associated to each estimator in Table 6). In particular, the estimated regression coefficients of the two technological variables (elettroratio and atmshare) are both negative and significant in most specifications. When it is not the case this could be due to functional misspecification which we tackle by specifying a polynomial form (equation 2).

\footnotetext{
${ }^{5}$ Since the panel is unbalanced the time index should be $t_{i}$. For ease of notation we decide to drop the index $i$ and use $t$ instead of $t_{i}$.

${ }^{6}$ Notice that the $\mathrm{AB}$ estimator requires the inclusion of the lagged dependent variable among the regressors.
} 
The inclusion of nonlinear effects (quadratic and cubic terms) significantly improves the fit. It is also worth noticing that the first-order (negative) coefficient of the electronic payment technology variables is always significant. However, it probably does not capture the whole marginal effect. Moreover, adding squares and cubes to our baseline model complicates a little the interpretation of the marginal effects. The marginal effect of $x$ on logcostratio in equation 2 is approximated by the following expression

$$
\frac{\Delta \text { logcostratio }}{\Delta x} \approx f(x)=\beta_{1}^{(x)}+2 \beta_{2}^{(x)} x+3 \beta_{3}^{(x)} x^{2}
$$

Since the marginal effect depends on $x$, it is of practical interest to test whether the marginal effects are zero when evaluated at some particular value of $x$, say the mean, the median or some other quantile. Let us then consider the following null hypothesis

$$
H_{0}: f(x)=0
$$

The alternative hypothesis depends on the variable we are considering. In particular, if $x=\{$ logwage $\}$

$$
H_{1}: f(x)>0
$$

while if $x=\{$ elettroratio, atmshare, $\log \mathrm{TA}\}$

$$
H_{1}: f(x)<0
$$

The results of the tests described above are collected in Table 7 for the static model and in Table 8 for the dynamic model. The results for the two model specifications 
are similar. We notice that the marginal effect of the atmshare variable is always non significant. With respect to the elettroratio variable we see that we consistently reject the null hypothesis (i.e. whether we consider mean or the three quartiles) only in the case of the pooling estimator. These results are confirmed also by the AB estimator. It is worth noticing that our specification tests suggest that between the FE estimator and pooled OLS we should favour the FE estimator. The same happens when we test FE against RE. In addition to that, the Sargan test suggests that the orthogonality conditions used for the $A B$ estimator are satisfied.

Table7 7 about here

Table 8 about here

\section{Nonparametric models}

The nonlinear specification in equation (2) allows us to describe the potential nonlinear nature of the marginal effects. However, a more sensible way to capture such nonlinear features is to use nonparametric estimation techniques, allowing us to overcome problems coming from the incorrect specification of the model's functional form. $7^{7}$

The general nonparametric model we use is defined as

$$
y_{i t}=m\left(\mathbf{x}_{i t}, i, t\right)+\varepsilon_{i t}
$$

where $\mathbf{x}_{i t}$ is a set of regressors as in equation (1). By means of a Taylor expansion of

\footnotetext{
${ }^{7}$ To the best of our knowledge, no off-the-shelf estimator can simultaneously deal with endogeneity and panel data in a nonparametric fashion. Hence, we rely on the results obtained in the parametric models as for endogeneity robustness checks.
} 
$m\left(\mathbf{x}_{i t}, i, t\right)$ about $\mathbf{x}$ we obtain the following approximation

$$
y_{i t} \approx m(\mathbf{x}, i, t)+\left(\mathbf{x}_{i t}-\mathbf{x}\right)^{\prime} \mathbf{g}(\mathbf{x}, i, t)+\varepsilon_{i t} .
$$

This approximation allows us to derive not only an estimator for $m(\mathbf{x}, i, t)$ but also an estimator for the marginal effects vector function $\mathbf{g}(\mathbf{x}, i, t)$. For the model in equation (4), we can derive the local linear kernel estimator (LLKE) via standard least squares theory. This is,

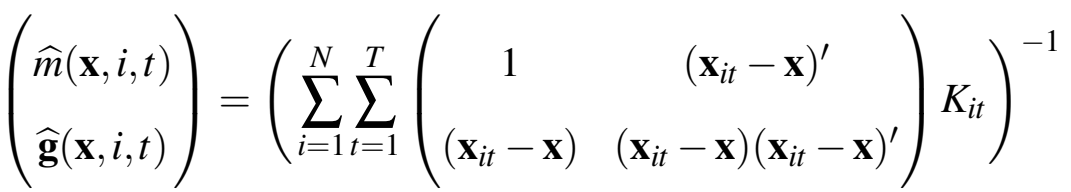

$$
\begin{aligned}
& \times \sum_{i=1}^{N} \sum_{t=1}^{T}\left(\begin{array}{c}
1 \\
\left(\mathbf{x}_{i t}-\mathbf{x}\right)
\end{array}\right) K_{i t, \mathbf{h}} y_{i t}
\end{aligned}
$$

where $K_{i t, \mathbf{h}}$ is a standard product kernel (Li \& Racine 2007) that depends also on a vector of bandwidth parameters $\mathbf{h} .87$ The LLKE provides us with an estimator of the conditional mean for each bank $i$ at time $t$, this is $\widehat{m}(\mathbf{x}, i, t)$. However, the merit of the LLKE is that it allows us to estimate the marginal effects associated to each variable in $\mathbf{x}_{i t}, \widehat{\mathbf{g}}(\mathbf{x}, i, t)$. It is universally known that the choice of the bandwidth in nonparametric estimation is crucial in determining the final results. Our problem is no exception to the rule. In order to choose the bandwidth we use the least squares cross-validation (LSCV) method and the Akaike information criterion (AIC). This approach, in conjunction with the LLKE delivers some interesting results. According to Hall et al. (2007), such a crossvalidation procedure is able to smooth away irrelevant regressors and to recognize when

\footnotetext{
${ }^{8}$ In the application we use the Gaussian kernel for continuous variables and the Li and Racine kernel for discrete variables. See Li \& Racine (2007) and references therein.
} 
continuous regressors enter the model in a linear fashion. Let us specify the vector of regressors as $\mathbf{x}_{i t}=\left(\mathbf{x}_{i t}^{c^{\prime}}, \mathbf{x}_{i t}^{o^{\prime}}, \mathbf{x}_{i t}^{u^{\prime}}\right)^{\prime}$, where the superscripts $c, o$ and $u$ indicate continuous, discrete ordered and discrete unordered regressors respectively. The bandwidth's upper bound associated to a continuous variable is infinite. This is clearly a theoretical bound and it cannot be observed in practice. However, when the bandwidth is sufficiently large and by graphical inspection, we can argue that the regressor enters the model linearly. This phenomenon can actually be observed in our results in Table 9 and in Figure 3 , The case of discrete regressors is quite different. The bandwidth associated to a discrete variable, whether ordered or unordered, takes values between zero and one. When the bandwidth reaches its upper bound the variable is smoothed away and it has no effect on the results. This fact justifies the fixed effects approach in Racine (2008). This is, we consider an unordered discrete variable associated with each bank, say, $x_{i t}^{u}=i$ and, whenever the associated bandwidth hits the upper bound, the variable is smoothed out and the data are poolable. This approach has been applied in a number of contexts by different authors. See for example Henderson et al. (2011), Henderson \& Simar (2005), Gyimah-Brempong \& Racine (2010), Gyimah-Brempong \& Racine (2014), Czekaj \& Henningsen (2013). We compare the results obtained via the LSCV approach with nonparametric estimates that use an improved AIC to calculate the optimal bandwidth (see Hurvich et al. 1998). The results of the nonparametric estimates are collected in Figures 3 to $69^{9}$ More precisely, Figure 3 contains the LSCV-based nonparametric estimates for the fixed effects model and Figure 4 its associated marginal effects, while Figure 5 contains the AIC-based nonparametric estimates for the fixed effects model and Figure 6 its associated marginal effects. Each figure features a bootstrapped $95 \%$ confidence band. Finally, Table 9 contains the bandwidths associated to the nonparametric estimators and

\footnotetext{
${ }^{9}$ For ease of exposition, figures only include the results for the continuous variables.
} 
to each variable. The variables bank and year refer to the indices $i$ and $t$ in equation (3) respectively.

Figure 3 about here

Figure 4 about here

Figure 5 about here

Figure 6 about here

From Figure 3, Figure 4 and Table 9 we see that the effect of electroratio is linear and, therefore, its marginal effect on logcostratio is the same for any value of electroratio. We notice that the marginal effect is always negative. On the other hand, the marginal effect of atmshare is about zero for nearly all values of atmshare. The effect of atmshare gets negative for values of atmshare close to one. It is worth noticing that the confidence intervals get larger consistently with the fact that there are only few data corresponding to large values of atmshare. In those cases Henderson \& Parmeter 2007, pp. 214-215) suggest comparing the LSCV results with those obtained via AIC.

Table 9 about here

Given that this is the first study that tackles the issue by means of nonparametric techniques, it is of interest to check whether this new perspective is able to shed new light on the impact of IT innovation on banks' efficiency. Three considerations are in order with this respect. First, to some extent, results tend to agree under the two scenarios, the only notable exception being the behaviour of atmshare. The marginal 
effects associated to the parametric models (Table 6 and Table 7) confirm that banks with higher elettroratio are also the most cost-efficient. On the other hand, the results associated to the variable atmshare are more controversial as the marginal effects in the nonlinear specification are never significantly different from zero. The nonparametric estimates in Figures 3 to 6 confirm that elettroratio always plays a significant role in enhancing cost efficiency, while the marginal effect of atmshare could be either approximately constant around zero (Figure 4) or a constant positive value (Figure 6). Second, these findings support the view that elettroratio is the main driver of cost efficiency gains, rather than the endowment of ATMs alone (See Hypotheses 1 and 2 in Section II. . With respect to previous studies, this appears to be a new result. Third, the results for our other two control variables reveal the nonlinear nature for bank size $(\operatorname{logTA})$, while the variable associated to wages (logwage) is approximately linear. This suggests caution about the inclusion of bank size proxies in linear models for banks' cost efficiency. As pointed out in Section III. this corresponds exactly to the Italian case, where the nexus between efficiency and size is complex and depends on many different factors such as the bank's geographical location and its ownership structure (Giordano \& Lopes 2009).

\section{Savings}

The estimates from our models can be used to estimate variations in logcostratio between 2006 and 2010. We can define

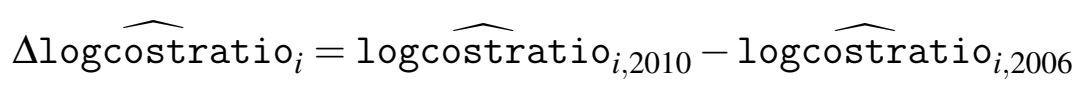


as the cost savings of the bank with respect to a technological variable, ceteris paribus. Figures 7, 8, 9 and 10 report estimated savings stemming from a change in atmshare and elettroratio in the linear parametric, cubic parametric and the nonparametric models respectively. Such a comparison gives rise to interesting insights. We notice a large difference in the results of the two parametric specifications. Looking at Figure 7, one should conclude that atmshare is not able to produce an effect on savings, while increasing elettroratio produces some saving effect. On the other hand, the cubic model displays larger savings for both technological variables (Figure 8). Finally, for the nonparametric models in Figure 9 and in Figure 10 we notice that the effect of atmshare is nearly zero, while an increasing variation in elettroratio produces a decrease in $\Delta \log \widehat{\text { ostratio }_{i}}$.

Figure 7 about here

Figure 8 about here

Figure 9 about here

Figure 10 about here

\section{Conclusions}

This paper tackles the issue of cost inefficiency reduction associated to the use of full automated payment processing procedures. The issue of innovation in payments is at the core of the SEPA project and, more in general, of the Digital Agenda for Europe. The SEPA scale goes beyond inter-bank level and cash management (which also would get benefits), and in specific cases also encompasses interfacing with end-users. Cash 
and other paper based payment instruments are still widely adopted in Europe. In this field, the migration from the legacy credit transfer and direct debit schemes to the SEPA products will allow enhancing end-to-end payments, using common message formats in the bank-to-customer/firm domain and customer servicing channels associated with payments initiation, reconciliation and cash management services. In this context, banks can better keep their clients and increase stable liabilities/deposits which are also important to mitigate liquidity risks. The financial industry has a pivotal role in the provision of this kind of services. In this paper we have shown some relevant empirical evidence which confirms the positive impact of full automated processing procedures for overall operating costs. In particular, we find strong evidence that the diffusion of electronic payments effectively reduces cost inefficiency, while ATMs diffusion alone does not. We have obtained these results contrasting results obtained using both parametric and nonparametric estimation techniques. From a policy point of view, our conclusions are also relevant for the ongoing debate on the declining pattern of operating incomes in the Italian banking system. During the years under investigation, the Italian banking system has experienced a consistent drop in operating net earnings which has been mainly driven by a contraction in the level of revenues from financial services. In the context of the current credit crisis (and given the strict regulations imposed by the Basel agreements), such a pattern will be hardly reversed unless banking activities will improve cost efficiency (Panetta 2013). Our results show that IT innovation is effective in enhancing cost efficiency. This indicates that cost reduction can be achieved by relying heavily on virtual services to depositors (remote banking) and enlarging the supply of electronic payment channels. 


\section{References}

Arellano, M. \& Bond, S. (1991), 'Some tests of specification for panel data: Monte Carlo evidence and an application to employment equations', Review of Economic Studies (58), 277-297.

Ayadi, R., Arbak, E., Groen, W. P. d. \& Llewellyn, D. (2012), 'Regulation of European banks and business models: Towards a new paradigm', Center for European Policy Studies .

Bank of Italy (2012), 'Institutional issue. The social costs of payment instruments in Italy'.

Bank of Italy (2014), 'Annual Report'.

Berger, A. N. (2003), 'The economic effects of technological progress: Evidence from the banking industry', Journal of Money, Credit, Banking (35), 141-176.

Berger, A. N. \& Humphrey, D. (1997), 'Efficiency of financial institutions: International survey and directions for future research', European Journal of Operational Research (87), 175-212.

Bikker, J. A. (2004), Competition and Efficiency in a Unified European Banking Market, Edward Elgar, Cheltenham, UK - Northampton, MA, USA.

Carbó-Valverde, S., Chakravorti, S. \& Rodriguez Fernandez, F. (2010), 'Regulating two-sided markets: An empirical investigation', Working Paper Series - Federal Reserve Bank of Chicago . 
Carbó-Valverde, S., Humphrey, D. B. \& Lopez, R. (2006), Electronic payments and ATMs: Changing technology and cost efficiency in banking, in M. Balling, F. Lierman \& A. Mullineaux, eds, 'Competition and Profitability in European Financial Services. Strategic, Systemic and Policy Issues', Rutledge, chapter 8.

Casolaro, L. \& Gobbi, L. (2004), 'Information technology and productivity changes in the Italian banking industry', Temi di Discussione della Banca d'Italia 489.

Croissant, Y. \& Millo, G. (2008), 'Panel data econometrics in R: The plm package', Journal of Statistical Software 27(2).

URL: http://www.jstatsoft.org/v27/i02/

Czekaj, T. \& Henningsen, A. (2013), 'Panel data specifications in nonparametric kernel regression: An application to production functions', IFRO Working Paper (5).

Frame, W. S. \& White, L. J. (2012), Technological change, financial innovation, and diffusion in banking, in A. N. Berger, P. Molyneux \& J. O. S. Wilson, eds, 'The Oxford Handbook of Banking, 2nd edition', Oxford University Press, chapter 19.

Fung, B., Molico, M. \& Stuber, G. (2014), 'Electronic money and payments: Recent developments and issues', Bank of Canada Discussion Paper (2).

Giordano, L. \& Lopes, A. (2009), Measuring the efficiency of the banking system in a dualistic economy: Evidence from the Italian case, in D. Silipo, ed., 'The Banks and the Italian Economy', Springer.

Gyimah-Brempong, K. \& Racine, J. S. (2010), 'Aid and investment in LDCs: A robust approach', The Journal of International Trade and Economic Development: An International Comparative Review 19, 319-394. 
Gyimah-Brempong, K. \& Racine, J. S. (2014), 'Aid and economic growth: A robust approach', Journal of African Development 16, 1-35.

Hall, P., Li, Q. \& Racine, J. S. (2007), 'Nonparametric estimation of regression functions in the presence of irrelevant regressors', Review of Economics and Statistics 89, 784-789.

Hasan, I., de Renzis, T. \& Schmiedel, H. (2013), 'Retail payments and the real economy', European Central Bank - Working Paper Series 1572.

Hasan, I., Schmiedel, H. \& Song, L. (2012), 'Retail payment and bank performance', Journal of Financial Services and Research 41, 163-195.

Hayfield, T. \& Racine, J. S. (2008), 'Nonparametric econometrics: The np package', Journal of Statistical Software 27(5).

URL: http://www.jstatsoft.org/v27/i05/

Haynes, M. \& Thompson, S. (2000), 'The productivity impact of IT development: an empirical evaluation of ATM introduction', Oxford Bulletin of Economics and Statistics 62, 607-619.

Henderson, D. J., Papageorgiou, C. \& Parmeter, C. F. (2011), 'Growth empirics without parameters', Economic Journal 122, 125-154.

Henderson, D. J. \& Parmeter, C. F. (2007), Applied Nonparametric Econometrics, Princeton University Press.

Henderson, D. J. \& Simar, L. (2005), 'A fully nonparametric stochastic frontier model for panel data', Discussion Paper, Institute de Statistique, Université Catholique de Louvaine (0417). 
Humphrey, D., Willesson, M., Bergendahl, G. \& Lindblom, T. (2006), 'Benefits from a changing payment technology in European banking', Journal of Banking and Finance 30, 1631-1652.

Hurvich, C. M., Simonoff, J. S. \& Tsai, G.-L. (1998), 'Smoothing parameter selection in nonparametric regression using an improved Akaike information criterion', Journal of the Royal Statistical Society, series B 60, 271-293.

Kwan, S. H. \& Eisenbeis, A. (1996), 'An analysis of inefficiencies in banking: a stochastic cost frontier approach', Economic Review, Federal Reserve Bank of San Francisco pp. 16-26.

Li, Q., Lin, J. \& Racine, J. S. (2013), 'Optimal bandwidth selection for nonparametric conditional distribution and quantile functions', Journal of Business and Economic Statistics 31, 57-65.

Li, Q. \& Racine, J. S. (2007), Nonparametric Econometrics: Theory and Practice, Princeton University Press.

Li, Q. \& Racine, J. S. (2008), 'Nonparametric estimation of conditional CDF and quantile functions with mixed categorical and continuous data', Journal of Business and Economic Statistics 26, 423-434.

Ou, C.-S., Hung, S.-Y., Yen, D. C. \& Liu, F.-C. (2005), Can automatic teller machine investment improve bank cost efficiency?, in 'Proceedings of the Third Workshop on Knowledge Economy and Electronic Commerce'.

URL: http://moe.ecrc.nsysu.edu.tw/English/workshopE/2005/SYS-06.pdf

Ou, C.-S., Hung, S.-Y., Yen, D. C. \& Liu, F.-C. (2009), 'Impact of ATM intensity on 
cost efficiency: An empirical evaluation in Taiwan', Information and Management 46, 442-447.

Panetta, F. (2013), Banche, finanza, crescita, in 'Intervento del Vice Direttore Generale della Banca d'Italia in Occasione del Convegno: Oltre la Crisi: Quale Futuro per le Banche Italiane?'.

Racine, J. S. (2008), ‘Nonparametric econometrics: A primer', Foundations and Trends in Econometrics 3, 1-88.

Schmiedel, H., Kostova, G. \& Ruttenberg, W. (2012), 'The social and private costs of retail payment instruments, a European perspective', ECB occasional paper (137).

Spong, K., Sullivan, R. \& DeYoung, R. (1995), 'What makes a bank efficient? A look at financial characteristics and bank management and ownership structure', Financial Industry Perspectives, Federal Reserve Bank of Kansas City (2), 1-19. 
Innovation and Cost Efficiency in the Banking Industry:

the Role of Electronic Payments: Figures 


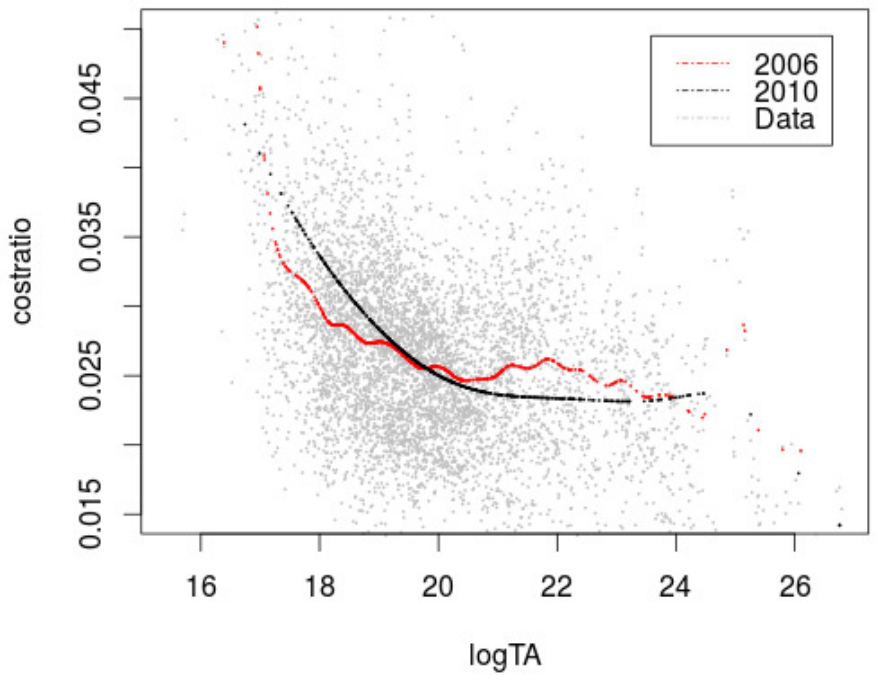

Figure 1. Cost efficiency and bank size in 2006 and 2010 

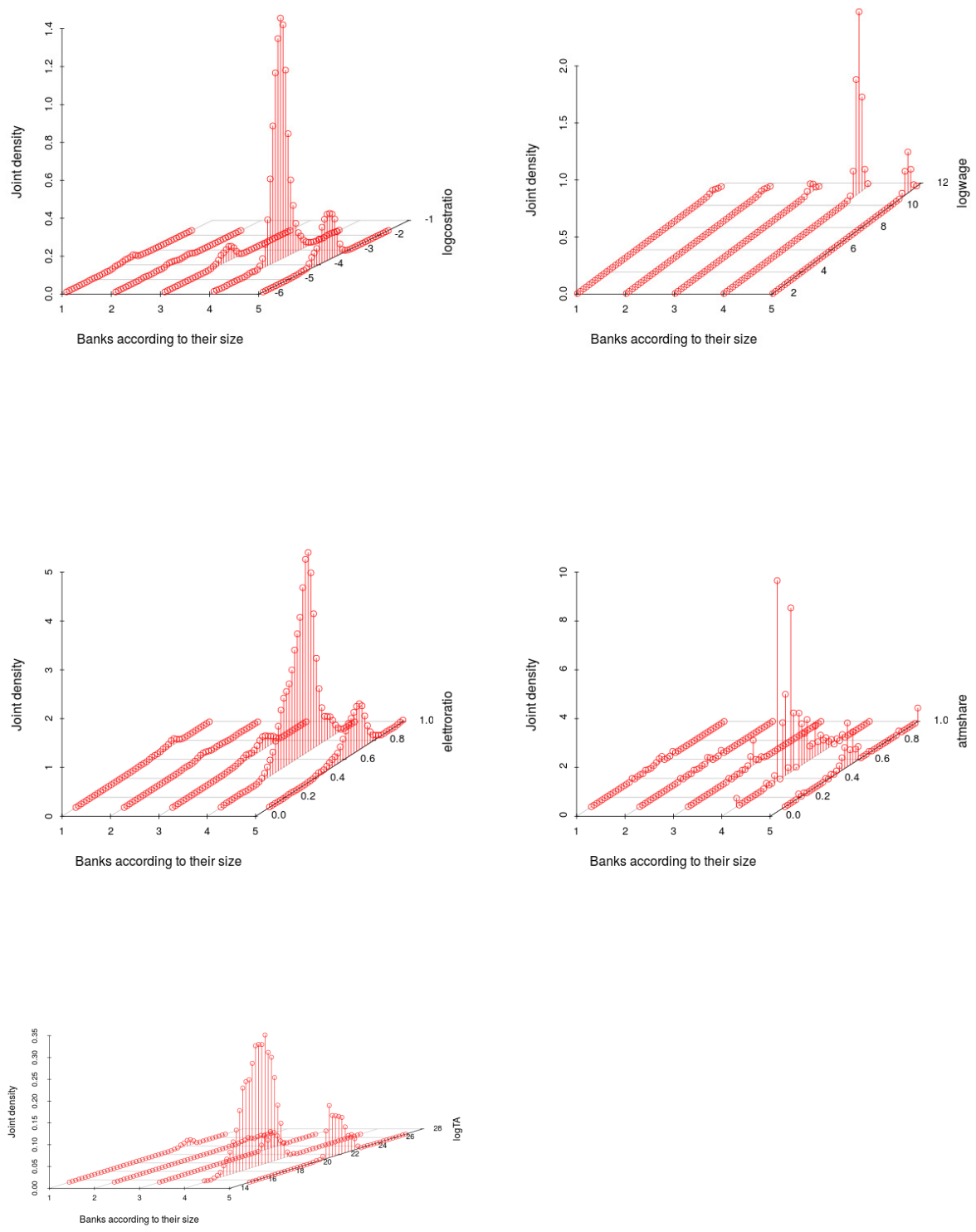

Figure 2. Nonparametric joint densities of logcostratio, logwage, electroratio, atmshare, logTA and size: in the horizontal axis 1 corresponds to major banks, 2 to big banks, 3 to average banks, 4 to minor banks, 5 to small banks. 

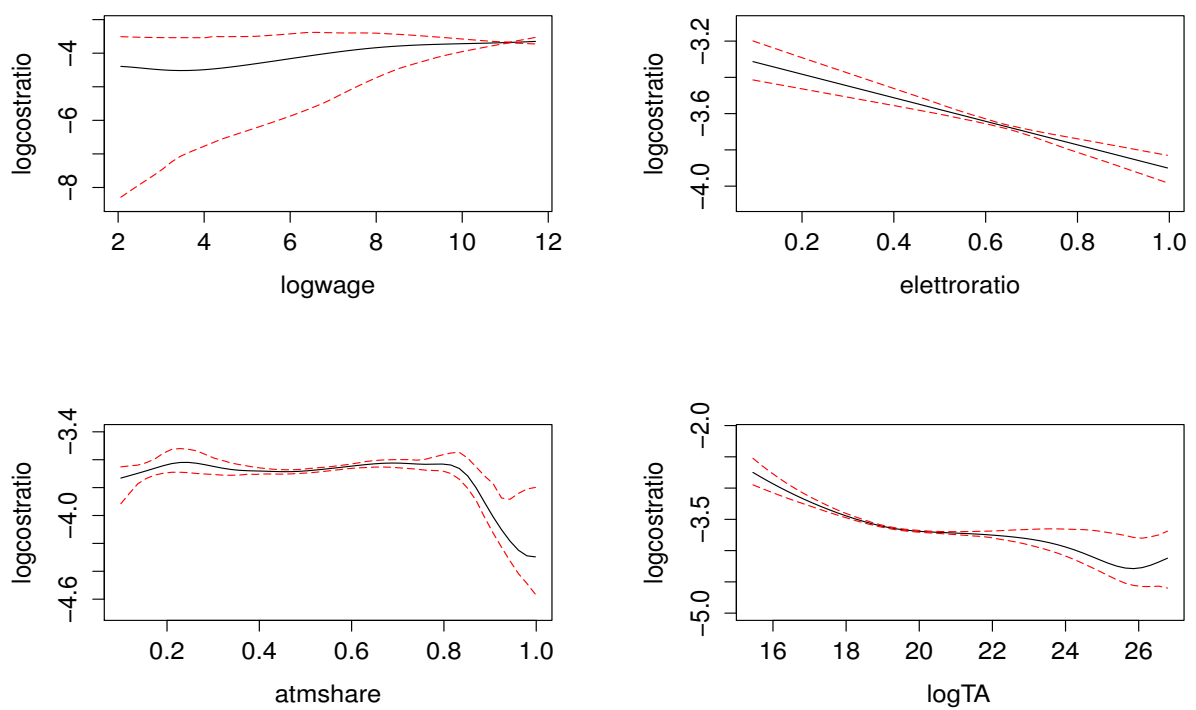

Figure 3. Estimates of FE nonparametric regression with LSCV.
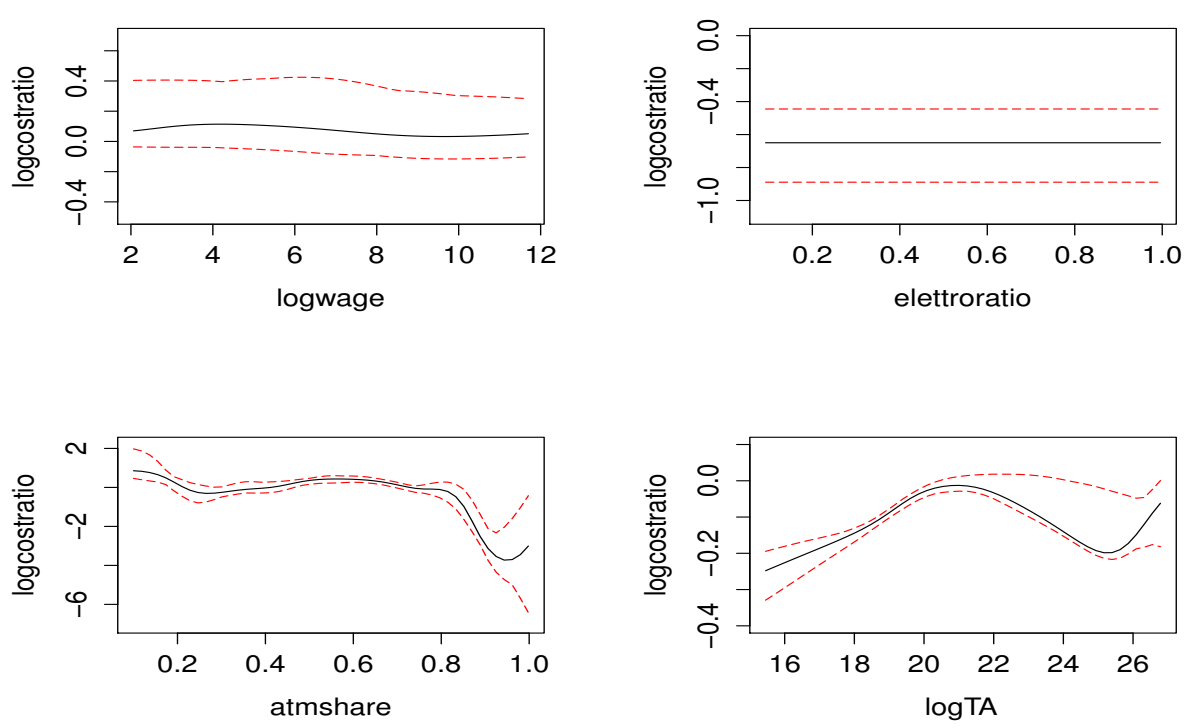

Figure 4. Marginal effects of FE nonparametric regression with LSCV. 

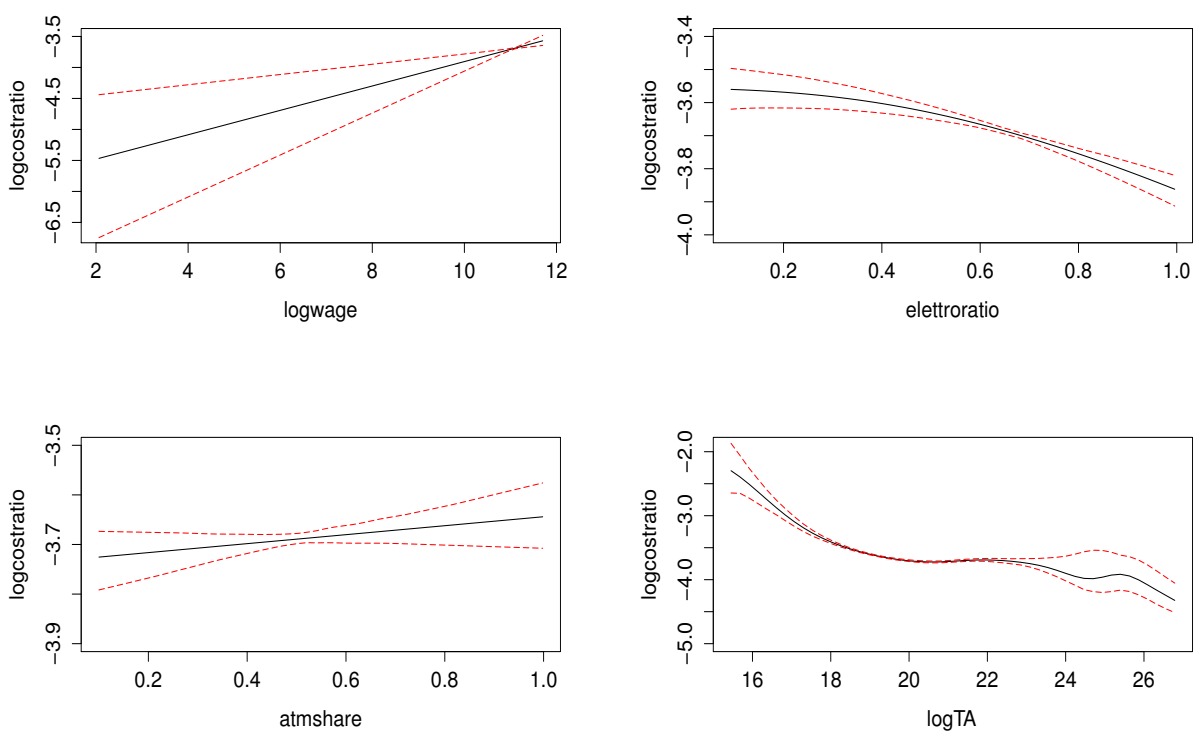

Figure 5. Estimates of FE nonparametric regression with AIC.
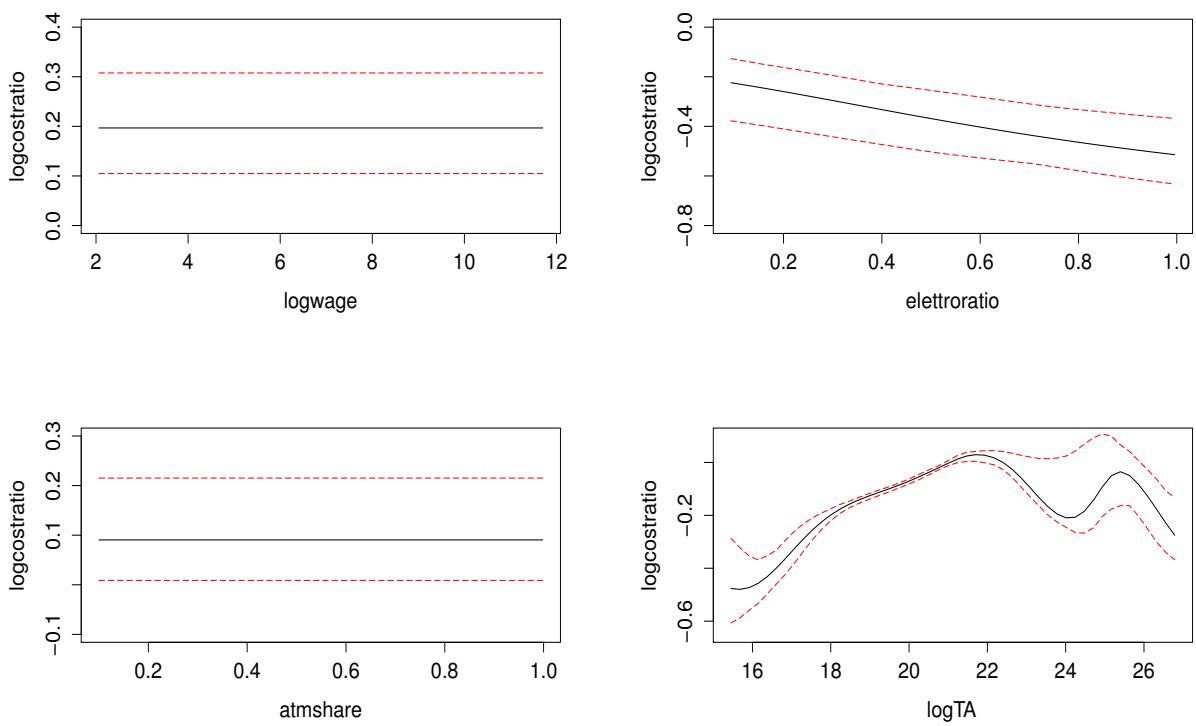

Figure 6. Marginal effects of FE nonparametric regression with AIC. 

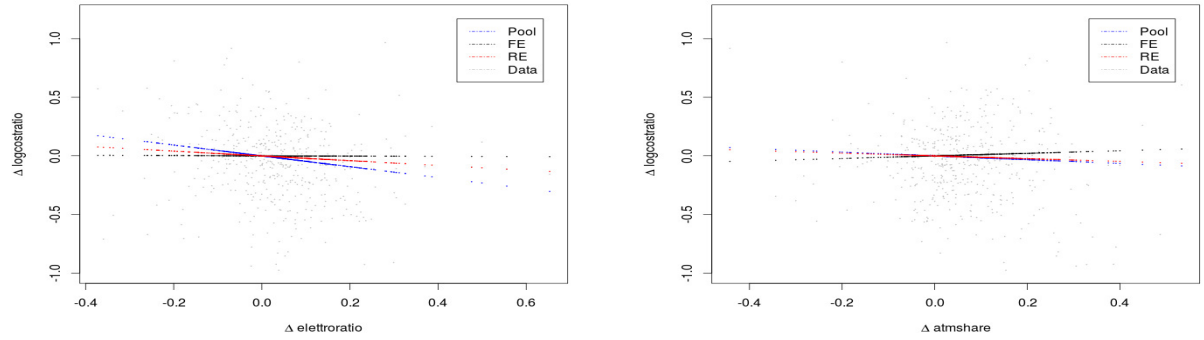

Figure 7. Savings for the linear parametric model.
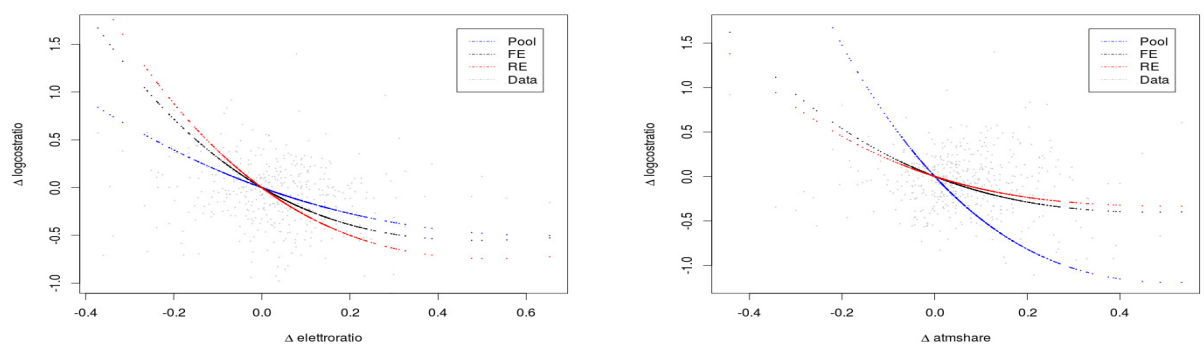

Figure 8. Savings for the cubic parametric model.
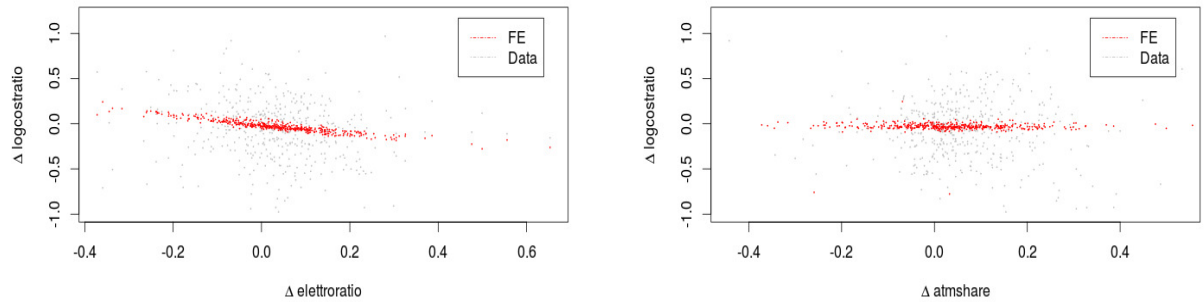

Figure 9. Savings for the nonparametric model with LSCV. 

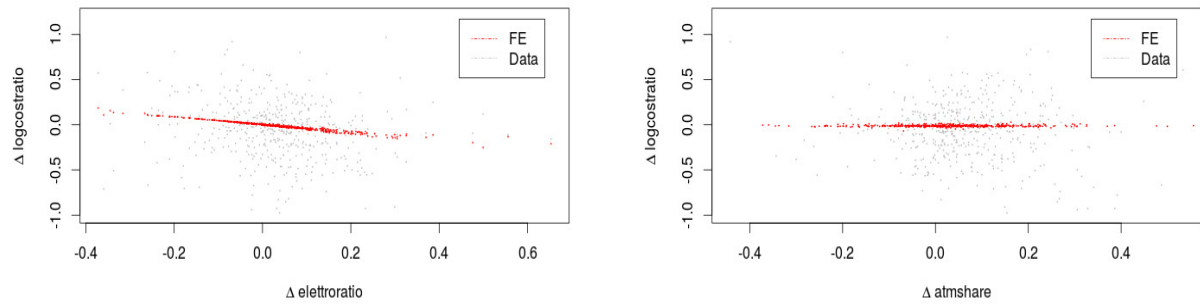

Figure 10. Savings for the nonparametric model with AIC. 
Innovation and Cost Efficiency in the Banking Industry:

the Role of Electronic Payments: Tables 
TABLE 1

Variable definitions

\begin{tabular}{ll}
\hline \hline Variable & Definitions \\
\hline logcostratio & Natural logarithm of the ratio of operating costs to total assets. \\
$\begin{array}{l}\text { logwage } \\
\text { elettroratio }\end{array}$ & $\begin{array}{l}\text { Ratural logarithm of wages. } \\
\text { atmshare }\end{array}$ \\
$\begin{array}{l}\text { Ratio of the number of ATMs to the number of physical branches } \\
\text { and ATMs. }\end{array}$ \\
$\begin{array}{l}\text { Natural log of total assets (TA); TA includes cash balances, financial assets } \\
\text { for trading, loans with banks and customers, financial investments, property, } \\
\text { plant and equipment and intangible assets. }\end{array}$ \\
\hline \hline
\end{tabular}

TABLE 2

Correlation matrix

\begin{tabular}{lccccc}
\hline \hline & costratio & wage & elettroratio & atmshare & .1 \\
\hline costratio & 1 & 0.062 & -0.221 & -0.195 & -0.098 \\
wage & 0.062 & 1 & 0.147 & 0.055 & 0.096 \\
elettroratio & -0.221 & 0.147 & 1 & -0.005 & 0.054 \\
atmshare & -0.195 & 0.055 & -0.005 & 1 & 0.112 \\
TA & -0.098 & 0.096 & 0.054 & 0.112 & 1 \\
\hline \hline
\end{tabular}


TABLE 3

Descriptive statistics (full sample)

\begin{tabular}{lcccccc}
\hline \hline Variable & Minimum & 1st Quantile & Median & Mean & 3rd Quantile & Maximum \\
\hline costratio & 0.003 & 0.022 & 0.026 & 0.027 & 0.030 & 0.186 \\
wage & 0.008 & 61.010 & 66.080 & 66.440 & 71.370 & 126.500 \\
elettroratio & 0.093 & 0.592 & 0.658 & 0.644 & 0.704 & 0.996 \\
atmshare & 0.100 & 0.455 & 0.500 & 0.502 & 0.550 & 0.998 \\
TA & 0.005 & 0.155 & 0.385 & 3.484 & 1.242 & 430.000 \\
\hline \hline
\end{tabular}

Note: The variable wage is expressed in thousands of Euros, while the variable TA is expressed in billions of Euros. 
TABLE 4

Descriptive statistics by year

\begin{tabular}{|c|c|c|c|c|c|c|}
\hline Variable & Minimum & 1st Quantile & Median & Mean & 3rd Quantile & Maximum \\
\hline \multicolumn{7}{|c|}{ Year 2006} \\
\hline costratio & 0.003 & 0.023 & 0.026 & 0.027 & 0.030 & 0.186 \\
\hline wage & 0.528 & 56.560 & 61.440 & 61.210 & 65.720 & 111.100 \\
\hline elettroratio & 0.126 & 0.560 & 0.636 & 0.620 & 0.685 & 0.996 \\
\hline atmshare & 0.100 & 0.422 & 0.480 & 0.467 & 0.525 & 0.995 \\
\hline $\mathrm{TA}$ & 0.005 & 0.131 & 0.321 & 2.905 & 0.970 & 216.000 \\
\hline \multicolumn{7}{|c|}{ Year 2007} \\
\hline costratio & 0.010 & 0.022 & 0.026 & 0.028 & 0.030 & 0.152 \\
\hline wage & 24.870 & 59.480 & 64.180 & 64.860 & 68.720 & 113.900 \\
\hline elettroratio & 0.093 & 0.575 & 0.645 & 0.630 & 0.693 & 0.994 \\
\hline atmshare & 0.182 & 0.429 & 0.484 & 0.472 & 0.526 & 0.997 \\
\hline $\mathrm{TA}$ & 0.006 & 0.124 & 0.342 & 2.901 & 0.992 & 395.000 \\
\hline \multicolumn{7}{|c|}{ Year 2008} \\
\hline costratio & 0.003 & 0.022 & 0.027 & 0.028 & 0.031 & 0.130 \\
\hline wage & 11.520 & 63.150 & 67.530 & 68.260 & 72.370 & 120.700 \\
\hline elettroratio & 0.117 & 0.606 & 0.664 & 0.651 & 0.706 & 0.973 \\
\hline atmshare & 0.100 & 0.480 & 0.525 & 0.534 & 0.579 & 0.998 \\
\hline $\mathrm{TA}$ & 0.016 & 0.174 & 0.433 & 3.711 & 1.509 & 430.000 \\
\hline \multicolumn{7}{|c|}{ Year 2009} \\
\hline costratio & 0.009 & 0.022 & 0.026 & 0.026 & 0.030 & 0.141 \\
\hline wage & 0.008 & 63.440 & 67.940 & 68.610 & 72.770 & 110.900 \\
\hline elettroratio & 0.239 & 0.606 & 0.672 & 0.659 & 0.715 & 0.991 \\
\hline atmshare & 0.222 & 0.483 & 0.519 & 0.524 & 0.565 & 0.998 \\
\hline $\mathrm{TA}$ & 0.024 & 0.186 & 0.445 & 3.666 & 1.419 & 422.000 \\
\hline \multicolumn{7}{|c|}{ Year 2010} \\
\hline costratio & 0.006 & 0.021 & 0.025 & 0.026 & 0.029 & 0.125 \\
\hline wage & 0.949 & 65.630 & 69.390 & 70.150 & 74.200 & 120.500 \\
\hline elettroratio & 0.216 & 0.618 & 0.679 & 0.665 & 0.723 & 0.991 \\
\hline atmshare & 0.111 & 0.486 & 0.522 & 0.524 & 0.565 & 0.998 \\
\hline $\mathrm{TA}$ & 0.019 & 0.189 & 0.453 & 4.396 & 1.402 & 416.000 \\
\hline
\end{tabular}

Note: The variable wage is expressed in thousands of Euros, while the variable TA is expressed in billions of Euros. 
TABLE 5

Descriptive statistics by bank size

\begin{tabular}{|c|c|c|c|c|c|c|}
\hline Variable & Minimum & 1st Quantile & Median & Mean & 3rd Quantile & Maximum \\
\hline \multicolumn{7}{|c|}{ Minor Banks } \\
\hline costratio & 0.003 & 0.023 & 0.026 & 0.028 & 0.031 & 0.186 \\
\hline wage & 0.528 & 60.650 & 65.720 & 66.140 & 70.980 & 120.700 \\
\hline elettroratio & 0.117 & 0.582 & 0.656 & 0.638 & 0.698 & 0.889 \\
\hline atmshare & 0.100 & 0.440 & 0.500 & 0.489 & 0.540 & 0.875 \\
\hline $\mathrm{TA}$ & 0.005 & 0.117 & 0.256 & 0.373 & 0.509 & 3.389 \\
\hline \multicolumn{7}{|c|}{ Small Banks } \\
\hline costratio & 0.008 & 0.020 & 0.024 & 0.025 & 0.029 & 0.044 \\
\hline wage & 27.500 & 61.770 & 66.510 & 66.880 & 71.070 & 120.400 \\
\hline elettroratio & 0.093 & 0.617 & 0.673 & 0.659 & 0.716 & 0.996 \\
\hline atmshare & 0.192 & 0.508 & 0.532 & 0.546 & 0.566 & 0.998 \\
\hline $\mathrm{TA}$ & 0.576 & 1.788 & 2.801 & 3.664 & 4.536 & 23.860 \\
\hline \multicolumn{7}{|c|}{ Average Banks } \\
\hline costratio & 0.015 & 0.020 & 0.023 & 0.023 & 0.027 & 0.036 \\
\hline wage & 0.008 & 65.670 & 70.610 & 69.250 & 75.200 & 95.140 \\
\hline elettroratio & 0.471 & 0.646 & 0.696 & 0.683 & 0.732 & 0.807 \\
\hline atmshare & 0.399 & 0.519 & 0.536 & 0.537 & 0.562 & 0.625 \\
\hline $\mathrm{TA}$ & 8.132 & 11.170 & 17.260 & 17.780 & 22.240 & 38.660 \\
\hline \multicolumn{7}{|c|}{ Big Banks } \\
\hline costratio & 0.007 & 0.018 & 0.021 & 0.021 & 0.026 & 0.037 \\
\hline wage & 12.380 & 60.400 & 66.820 & 66.850 & 76.070 & 90.950 \\
\hline elettroratio & 0.532 & 0.688 & 0.743 & 0.716 & 0.754 & 0.789 \\
\hline atmshare & 0.511 & 0.536 & 0.548 & 0.558 & 0.568 & 0.693 \\
\hline $\mathrm{TA}$ & 10.640 & 20.390 & 27.290 & 27.730 & 33.460 & 44.620 \\
\hline \multicolumn{7}{|c|}{ Major Banks } \\
\hline costratio & 0.007 & 0.016 & 0.020 & 0.021 & 0.028 & 0.035 \\
\hline wage & 11.520 & 68.020 & 74.570 & 72.570 & 82.560 & 108.100 \\
\hline elettroratio & 0.502 & 0.611 & 0.640 & 0.660 & 0.718 & 0.890 \\
\hline atmshare & 0.550 & 0.570 & 0.618 & 0.630 & 0.696 & 0.750 \\
\hline TA & 22.220 & 77.250 & 94.930 & 167.300 & 208.000 & 430.000 \\
\hline
\end{tabular}
is expressed in billions of Euros. 


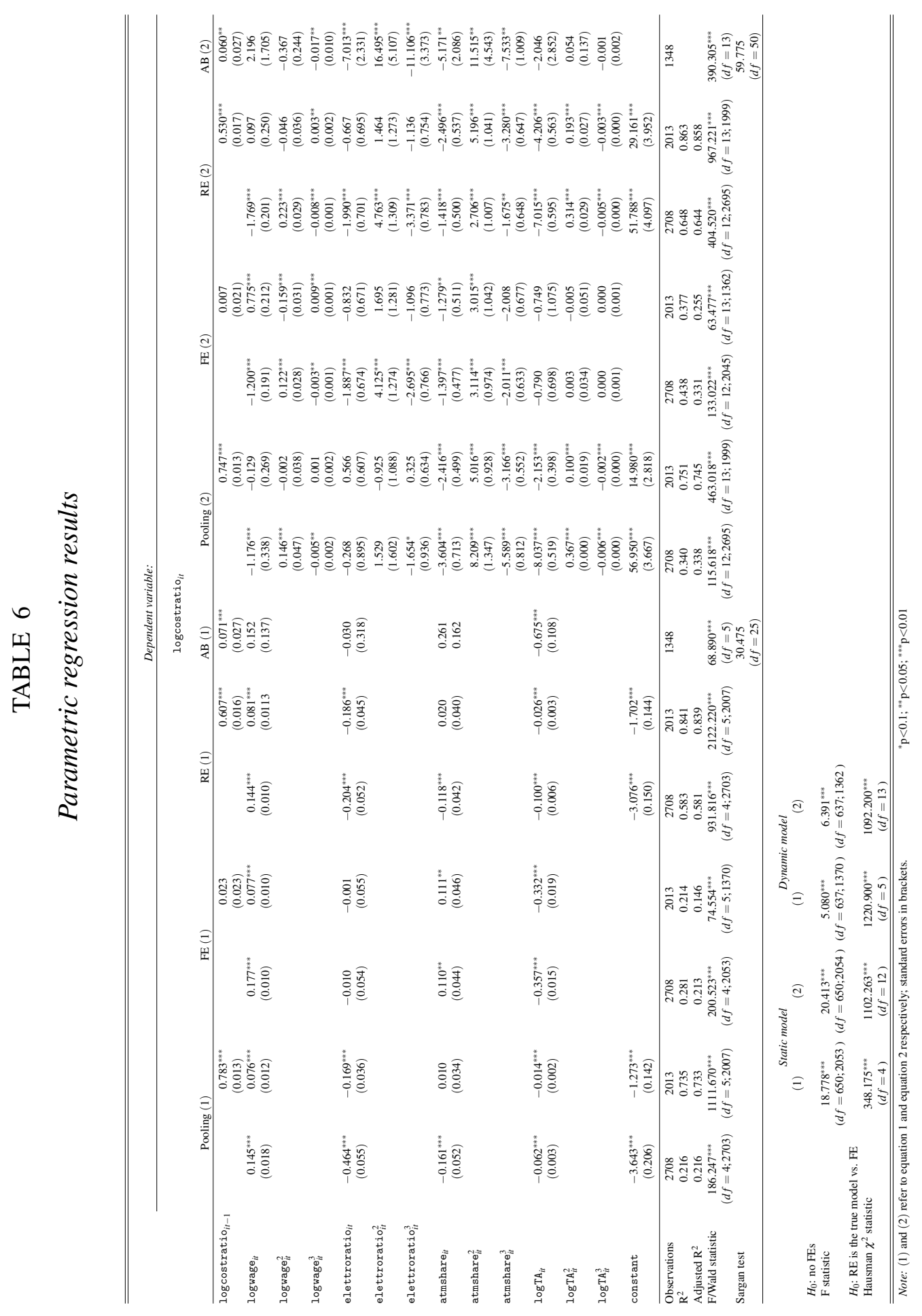




\section{TABLE 7}

Marginal effects in the static polynomial model

\begin{tabular}{|c|c|c|c|c|}
\hline & \multicolumn{4}{|c|}{$f(x)$} \\
\hline & $x=\bar{x}$ & $x=q_{0.25}$ & $x=q_{0.50}$ & $x=q_{0.75}$ \\
\hline & \multicolumn{4}{|c|}{$x=$ logwage } \\
\hline Pooling & $\begin{array}{c}9.535^{* * *} \\
(0.031)\end{array}$ & $\begin{array}{c}10.089^{* * *} \\
(0.029)\end{array}$ & $\begin{array}{c}9.429^{* * *} \\
(0.031)\end{array}$ & $\begin{array}{c}8.805^{* * *} \\
(0.033)\end{array}$ \\
\hline $\mathrm{FE}$ & $\begin{array}{c}20.770^{* * *} \\
(0.023)\end{array}$ & $\begin{array}{c}21.779^{* * *} \\
(0.022)\end{array}$ & $\begin{array}{c}20.581^{* * *} \\
(0.024)\end{array}$ & $\begin{array}{c}19.493^{* * *} \\
(0.025)\end{array}$ \\
\hline \multirow[t]{2}{*}{$\mathrm{RE}$} & $\begin{array}{c}13.412^{* * *} \\
(0.023)\end{array}$ & $\begin{array}{c}14.397^{* * *} \\
(0.022)\end{array}$ & $\begin{array}{c}13.228^{* * *} \\
(0.023)\end{array}$ & $\begin{array}{c}12.176^{* * *} \\
(0.025)\end{array}$ \\
\hline & \multicolumn{4}{|c|}{$x=$ elettroratio } \\
\hline Pooling & $\begin{array}{c}-5.529^{* * *} \\
(0.064)\end{array}$ & $\begin{array}{c}-2.698^{* * *} \\
(0.072)\end{array}$ & $\begin{array}{c}-6.373^{* * *} \\
(0.063)\end{array}$ & $\begin{array}{c}-8.138^{* * *} \\
(0.071)\end{array}$ \\
\hline FE & $\begin{array}{c}1.140 \\
(0.063)\end{array}$ & $\begin{array}{c}2.234 \\
(0.073)\end{array}$ & $\begin{array}{c}0.647 \\
(0.060)\end{array}$ & $\begin{array}{c}-1.466^{*} \\
(0.060)\end{array}$ \\
\hline \multirow[t]{2}{*}{$\mathrm{RE}$} & $\begin{array}{c}-0.814 \\
(0.061)\end{array}$ & $\begin{array}{l}1.490 \\
(0.071)\end{array}$ & $\begin{array}{c}-1.716^{* *} \\
(0.059)\end{array}$ & $\begin{array}{c}-4.894^{* * *} \\
(0.061)\end{array}$ \\
\hline & \multicolumn{4}{|c|}{$x=$ atmshare } \\
\hline Pooling & $\begin{array}{c}6.038 \\
(0.068)\end{array}$ & $\begin{array}{c}6.081 \\
(0.065)\end{array}$ & $\begin{array}{c}6.069 \\
(0.068)\end{array}$ & $\begin{array}{c}4.915 \\
(0.072)\end{array}$ \\
\hline FE & $\begin{array}{c}3.677 \\
(0.057)\end{array}$ & $\begin{array}{c}3.293 \\
(0.057)\end{array}$ & $\begin{array}{c}3.668 \\
(0.057)\end{array}$ & $\begin{array}{c}3.705 \\
(0.055)\end{array}$ \\
\hline \multirow[t]{2}{*}{$\mathrm{RE}$} & $\begin{array}{c}0.564 \\
(0.056)\end{array}$ & $\begin{array}{c}0.055 \\
(0.056)\end{array}$ & $\begin{array}{c}0.550 \\
(0.056)\end{array}$ & $\begin{array}{c}0.681 \\
(0.055)\end{array}$ \\
\hline & \multicolumn{4}{|c|}{$x=\log \mathrm{TA}$} \\
\hline Pooling & $\begin{array}{c}-13.147^{* * *} \\
(0.004)\end{array}$ & $\begin{array}{c}-25.717^{\text {*** }} \\
(0.006)\end{array}$ & $\begin{array}{c}-16.674^{* * *} \\
(0.004)\end{array}$ & $\begin{array}{c}-2.389^{* * *} \\
(0.005)\end{array}$ \\
\hline FE & $\begin{array}{c}-25.296^{* * *} \\
(0.018)\end{array}$ & $\begin{array}{c}-28.926^{* * *} \\
(0.017)\end{array}$ & $\begin{array}{c}-26.071^{* * *} \\
(0.018)\end{array}$ & $\begin{array}{c}-22.529^{* * *} \\
(0.019)\end{array}$ \\
\hline $\mathrm{RE}$ & $\begin{array}{c}-12.770^{* * *} \\
(0.007)\end{array}$ & $\begin{array}{c}-22.278^{* * *} \\
(0.008)\end{array}$ & $\begin{array}{c}-14.937^{* * *} \\
(0.007)\end{array}$ & $\begin{array}{c}-5.720^{* * *} \\
(0.007)\end{array}$ \\
\hline
\end{tabular}

Note: $\bar{x}$ is the mean of $x$ while $q_{\alpha}$ is the $\alpha$-th quantile of $x$. Standard errors in brackets; ${ }^{*} \mathrm{p}<0.1 ;{ }^{* *} \mathrm{p}<0.05 ;{ }^{* * *} \mathrm{p}<0.01$. 
TABLE 8

Marginal effects in the dynamic polynomial model

\begin{tabular}{|c|c|c|c|c|}
\hline & \multicolumn{4}{|c|}{$f(x)$} \\
\hline & $x=\bar{x}$ & $x=q_{0.25}$ & $x=q_{0.50}$ & $x=q_{0.75}$ \\
\hline & \multicolumn{4}{|c|}{$x=$ logwage } \\
\hline Pooling & $\begin{array}{c}9.558^{* * *} \\
(0.023)\end{array}$ & $\begin{array}{c}9.845^{* * *} \\
(0.022)\end{array}$ & $\begin{array}{c}9.500^{* * *} \\
(0.023)\end{array}$ & $\begin{array}{c}9.133^{* * *} \\
(0.025)\end{array}$ \\
\hline $\mathrm{FE}$ & $\begin{array}{c}17.461^{* * *} \\
(0.027)\end{array}$ & $\begin{array}{c}17.745^{* * *} \\
(0.025)\end{array}$ & $\begin{array}{c}17.406^{* * *} \\
(0.027)\end{array}$ & $\begin{array}{c}17.066^{* * *} \\
(0.029)\end{array}$ \\
\hline $\mathrm{RE}$ & $\begin{array}{c}12.300^{* * *} \\
(0.026)\end{array}$ & $\begin{array}{c}12.614^{* * *} \\
(0.025)\end{array}$ & $\begin{array}{c}12.238^{* * *} \\
(0.026)\end{array}$ & $\begin{array}{c}11.858^{* * *} \\
(0.028)\end{array}$ \\
\hline \multirow[t]{2}{*}{$\mathrm{AB}$} & $\begin{array}{c}11.144^{* * *} \\
(0.043)\end{array}$ & $\begin{array}{c}9.900^{* * *} \\
(0.045)\end{array}$ & $\begin{array}{c}11.325^{* * *} \\
(0.043)\end{array}$ & $\begin{array}{c}11.846^{* * *} \\
(0.043)\end{array}$ \\
\hline & \multicolumn{4}{|c|}{$x=$ elettroratio } \\
\hline Pooling & $\begin{array}{c}-4.865^{\text {*** }} \\
(0.045)\end{array}$ & $\begin{array}{c}-3.637^{* * *} \\
(0.051)\end{array}$ & $\begin{array}{c}-5.154^{* * *} \\
(0.044)\end{array}$ & $\begin{array}{c}-5.273^{* * *} \\
(0.048)\end{array}$ \\
\hline $\mathrm{FE}$ & $\begin{array}{l}-0.205 \\
(0.065)\end{array}$ & $\begin{array}{c}0.288 \\
(0.076)\end{array}$ & $\begin{array}{l}-0.417 \\
(0.062)\end{array}$ & $\begin{array}{l}-1.253 \\
(0.061)\end{array}$ \\
\hline $\mathrm{RE}$ & $\begin{array}{c}-3.492^{* * *} \\
(0.056)\end{array}$ & $\begin{array}{c}-1.980^{* *} \\
(0.065)\end{array}$ & $\begin{array}{c}-3.994^{* * *} \\
(0.054)\end{array}$ & $\begin{array}{c}-5.187^{* * *} \\
(0.057)\end{array}$ \\
\hline \multirow[t]{2}{*}{$\mathrm{AB}$} & $\begin{array}{c}2.391 \\
(0.172)\end{array}$ & $\begin{array}{c}4.773 \\
(0.176)\end{array}$ & $\begin{array}{c}1.508 \\
(0.176)\end{array}$ & $\begin{array}{c}-1.456^{*} \\
(0.210)\end{array}$ \\
\hline & \multicolumn{4}{|c|}{$x=$ atmshare } \\
\hline Pooling & $\begin{array}{c}4.930 \\
(0.046)\end{array}$ & $\begin{array}{l}4.048 \\
(0.045)\end{array}$ & $\begin{array}{c}4.917 \\
(0.046)\end{array}$ & $\begin{array}{c}4.748 \\
(0.048)\end{array}$ \\
\hline FE & $\begin{array}{c}3.890 \\
(0.059)\end{array}$ & $\begin{array}{c}3.651 \\
(0.059)\end{array}$ & $\begin{array}{c}3.886 \\
(0.059)\end{array}$ & $\begin{array}{c}3.790 \\
(0.056)\end{array}$ \\
\hline RE & $\begin{array}{c}4.428 \\
(0.054)\end{array}$ & $\begin{array}{c}3.623 \\
(0.054)\end{array}$ & $\begin{array}{c}4.410 \\
(0.054)\end{array}$ & $\begin{array}{c}4.432 \\
(0.055)\end{array}$ \\
\hline $\mathrm{AB}$ & $\begin{array}{c}5.380 \\
(0.129)\end{array}$ & $\begin{array}{c}5.029 \\
(0.125)\end{array}$ & $\begin{array}{c}5.379 \\
(0.129)\end{array}$ & $\begin{array}{c}5.047 \\
(0.131)\end{array}$ \\
\hline & \multicolumn{4}{|c|}{$x=\log \mathrm{TA}$} \\
\hline Pooling & $\begin{array}{c}-4.132^{* * *} \\
(0.003)\end{array}$ & $\begin{array}{c}-7.017^{* * *} \\
(0.005)\end{array}$ & $\begin{array}{c}-5.108^{* * *} \\
(0.003)\end{array}$ & $\begin{array}{c}-1.077 \\
(0.0003)\end{array}$ \\
\hline FE & $\begin{array}{c}-19.557^{* * *} \\
(0.022)\end{array}$ & $\begin{array}{c}-22.077^{* * *} \\
(0.022)\end{array}$ & $\begin{array}{c}-20.447^{* * *} \\
(0.022)\end{array}$ & $\begin{array}{c}-15.988^{* * *} \\
(0.025)\end{array}$ \\
\hline $\mathrm{RE}$ & $\begin{array}{c}-5.721^{* * *} \\
(0.005)\end{array}$ & $\begin{array}{c}-10.966^{* * *} \\
(0.007)\end{array}$ & $\begin{array}{c}-7.313^{* * *} \\
(0.005)\end{array}$ & $\begin{array}{l}-0.856 \\
(0.005)\end{array}$ \\
\hline $\mathrm{AB}$ & $\begin{array}{c}-11.397^{* * *} \\
(0.047)\end{array}$ & $\begin{array}{c}-14.381^{* * *} \\
(0.041)\end{array}$ & $\begin{array}{c}-11.957^{* * *} \\
(0.046)\end{array}$ & $\begin{array}{c}-9.641^{* * *} \\
(0.051)\end{array}$ \\
\hline
\end{tabular}

Note: $\bar{x}$ is the mean of $x$ while $q_{\alpha}$ is the $\alpha$-th quantile of $x$.

Standard errors in brackets; ${ }^{*} \mathrm{p}<0.1 ;{ }^{* *} \mathrm{p}<0.05 ;{ }^{* * *} \mathrm{p}<0.01$. 


\section{TABLE 9}

\section{Bandwidths}

\begin{tabular}{lcc}
\hline \hline & \multicolumn{2}{c}{ Dependent variable: logcostratio } \\
\cline { 2 - 3 } & LSCV & AIC \\
\hline logTA & 1.330 & 0.795 \\
logwage & 1.934 & $3,285,958.000$ \\
elettroratio & $64,888.950$ & 0.367 \\
atmshare & 0.065 & $418,817.700$ \\
bank & 0.000 & 0.001 \\
year & 0.559 & 1.000 \\
Observations & 2,708 & 2,708 \\
$\mathrm{R}^{2}$ & 0.994 & 0.973 \\
\hline \hline
\end{tabular}

